\title{
Won't Get Fooled Again: The Effects of Internal and External CSR ECO-Labeling
}

\author{
Jordy F. Gosselt ${ }^{1} \cdot$ Thomas van Rompay $^{1} \cdot$ Laura Haske $^{1}$
}

Received: 13 July 2016/Accepted: 16 March 2017/Published online: 24 March 2017

(c) The Author(s) 2017. This article is an open access publication

\begin{abstract}
Although most consumers are positive about socially responsible companies, in order to benefit from CSR efforts, effective and clear CSR communication is important. However, due to the constantly rising profusion of eco-labels, based on either own claims from the organization or claims made by an external third party, consumers may encounter difficulties in identifying truly responsible firms, which could result in less effective CSR initiatives, even for those responsible firms. Therefore, building on attribution theory, this study seeks to identify how uncertified internal CSR claims and external thirdparty CSR labels should be used in order to deter greenwashing and increase positive consumer evaluations. Within a 3 (external third-party CSR label: positive vs. negative vs. no label) $\times 2$ (uncertified internal CSR claim: present vs. absent) design, respondents are exposed to different coffee product packages measuring their attitude toward the brand, corporate credibility, purchase intention, and scent perception, as well as perceived attributional CSR motives. Overall, findings indicate that especially an external CSR label affects consumer responses toward the firm. Moreover, perceived CSR motives serve as a mediator between an external CSR label and corporate credibility and brand attitude, respectively. These findings warrant further consideration of introducing an external multilevel rating systems by governmental law.
\end{abstract}

Jordy F. Gosselt

j.f.gosselt@utwente.nl

1 Department of Communication Science, Faculty of Behavioral Sciences, University of Twente, P.O. Box 217, 7500 AE Enschede, The Netherlands
Keywords Corporate social responsibility · CSR · Green marketing $\cdot$ Green packaging $\cdot$ Greenwashing

\section{Introduction}

Corporate social responsibility (CSR) describes the concept of companies voluntarily incorporating environmental and social concerns in both their business operations and their interaction with stakeholders (Mickels 2009). By means of investments in green advertising and CSR, firms want to be perceived as environmentally friendly and socially involved in order to build up more positive brand attitudes and purchase intentions (Nyilasy et al. 2014). Indeed, CSR initiatives based on one of the three dimensions-social, ethical, or commercial-have been proven to affect consumer responses. For example, engaging in CSR may strengthen the relationship with consumers and may improve-over time-the corporate reputation (Du et al. 2010; Pomering and Johnson 2009), generates positive attitudes toward the firm, and may increase purchase behaviors (Becker-Olsen, Cudmore and Hill 2006; Du et al. 2010; Ellen et al. 2006; Sen and Bhatachharya 2001). Furthermore, although some studies found the opposite effect (e.g., Schuldt and Hannahan 2013), CSR communication may boost product perceptions. For example, in their study, Sörqvist et al. (2015) found that people may prefer the taste of an eco-friendly classified coffee over the taste of another-seemingly nonorganic-alternative, even if they are actually identical. Overall, environmentally friendly and organic products tend to be idealized and receive more positive evaluations than less environmentally friendly alternatives (Mondelaers et al. 2009; Sörqvist et al. 2015). Engaging in CSR may thus not only issue forth from the belief that companies have to contribute to a 
sustainable environment, but also from the idea that CSR efforts offer business benefits (Du et al. 2010).

As most consumers are positive about socially responsible companies (Xiaoli and Kwangjun 2007), scholars stress the importance of CSR communication in benefiting from CSR efforts (Mohr et al. 2001; Morsing and Schultz 2006; Xiaoli and Kwangjun 2007), for example by means of eco-labels. In real-life situations, eco-labels are attractive instruments for informing consumers about the environmental impact of their purchase decisions (Rashid 2009). However, due to the constantly rising profusion of eco-labels, based on either own claims from the organization or claims made by an external third party, consumers may encounter difficulties in identifying truly responsible firms, which results in less effective CSR initiatives, even for those responsible firms.

Therefore, and by building on attribution theory, this study seeks to identify how uncertified (internal) CSR claims and verified third-party (external) CSR labels should be used in order to deter greenwashing and increase positive consumer evaluations. In sum, this study explores the interplay between external CSR labels and internal CSR claims, and tests the prediction that an internal claim stressing CSR initiatives is only effective when backed up by an external label verifying such a claim. The outcome measures used in this study include corporate credibility, brand evaluation, product experience, purchase intentions, and perceived CSR motives.

\section{Eco-Labels}

Overall, eco-labels are indicators of the environmental performance of a company, developed to take away consumer confusion with respect to environmental friendliness claims (Giridhar 1998; Childs and Whiting 1998). Especially in the food sector, CSR communication serves as an effective tool for positively influencing consumer responses by the means of eco-labels (Thogersen 1999). Broadly, there are two types of eco-labels: (1) verified third-party labels (in this study referred to as "external CSR label") and (2) uncertified internal claims (further referred to as "internal CSR claim"). The Global Eco-labeling Network (GEN) (2004) provides a distinction between external and internal eco-labels by the following definition: "[An external label is] a label which identifies overall environmental preferences of a product within a product category based on life cycle considerations. In contrast to an uncertified internal environmental claim [internal CSR claim] statement developed by a manufacturer or service provider, an [external] eco-label is awarded by an impartial third party to products that meet established environmental leadership criteria" (p. 2). While independent third-party eco-labels (external CSR label) are thus based on compliance legislations with predetermined criteria that have to be verified by an independent competent authority, uncertified internal labels (internal CSR claim) are placed on the product by the manufacturer (Rashid 2009).

\section{External Label Versus Internal Claim}

With the growing awareness of the importance of a sustainable environment, and of the (financial) benefits which eco-labeled products might bring, the amount of those products and the variation of eco-labels increased enormously (Gallastegui 2002; Nyilasy et al. 2014). This profusion of CSR labels, whether justified or not, makes it difficult to distinguish which label is certified by a third party (external CSR label), and hence provides a more objective assessment of a company's CSR efforts, and which label is uncertified (internal CSR claim; Nyilasy et al. 2014; Parguel et al. 2011). Therefore, it is also of interest to investigate how consumers respond to the combination of such an external multilevel environmental performance rating and internal CSR efforts controlled by the company.

\section{The Self-promoters Paradox and Greenwashing}

A combination of external CSR communication and internal CSR communication could be strategic for shaping consumer responses, for aside from providing external CSR communication, it is suggested that organizations themselves need to communicate their CSR efforts in order to benefit (Parguel et al. 2011), and build a reputation that might protect (or restore) its image in the face of negative publicity (Vanhamme and Grobben 2009). However, communicating too much about CSR efforts can cause consumers to question a company's motives which creates skepticism toward the advertised message as well as toward the company itself, known as the self-promoters paradox (Ashforth and Gibbs 1990).

Furthermore, consumers often expect to get information about CSR efforts from both internal and external sources, but tend to perceive an external source as more credible than an internal source (Dawkins 2004). Consequently, consumers may evaluate companies more negatively when the CSR information is provided by the company itself and more positively when an external source informs them about CSR efforts (Kim 2011; Yoon et al. 2006). This may result from perceived self-interest in the eyes of consumers (i.e., self-promoter's paradox; Ashforth and Gibbs 1990): Information from the company is perceived as being selfinterested, calling into question the credibility of the message and the company itself, whereas external information creates less bias and is perceived as more credible. Another way of stating this is to say that perceptions of 
self-interestedness or incredibility may inspire perceptions of "greenwashing," defined as "the act of misleading consumers regarding the environmental practices of a company or the environmental benefits of a product or service" (Delmas and Burbano 2011, p. 66). According to Delmas and Burbano (2011), this encompasses two simultaneous behaviors: poor environmental performance and positive communication about these poor environmental performances. Thus, an internal CSR claim becomes misleading when firms do not live up to their promises (i.e., corporate greenwashing), which adversely impacts the CSR efforts and the corporation's reputation (Nyilasy et al. 2014). Looking back at the two simultaneous behaviors in which greenwashing companies engage: poor environmental performance and positive communication about these poor environmental performances, it becomes clear that when internal CSR claims are combined with a negative external CSR label, it is likely to instill perceptions of greenwashing, which has a negative impact on CSR efforts and causes skepticism (Delmas and Burbano 2011).

The greenwashing literature indeed suggests an interaction between environmental performance and green advertising (Delmas and Burbano 2011; TerraChoice 2010; Nyilasy et al. 2014; De Vries et al. 2013). A study conducted by Nyilasy et al. (2014) demonstrated that when an internal CSR claim (talk) and actual corporate environmental performance (deeds) are inconsistent, a perceived greenwashing effect occurs. The perceived greenwashing effect is defined as the consumer reactions to situations where green advertising messages and actual corporate social responsibility interact in inconsistent ways (Nyilasy et al. 2014). The existence of inconsistent CSR information could thus invite consumers to perceive a company as hypocritical and might thus jeopardize the image of the company affecting consumer attitudes and behaviors negatively (Wagner et al. 2009).

\section{The Mediating Role of Motives: Attribution Theory}

A possible underlying psychological mechanism that provides an explanation for the processing of external CSR labels and internal CSR claims in "green marketing" can be found in the Attribution Theory (Kelley 1973). Originating from the general psychology literature, the attribution theory investigates the underlying causal explanations people give when confronted with other people's behaviors within social environments (Kelley 1973). The theory states that individuals attribute observed behavior either to a person's internal disposition (e.g., a characteristic) or to external constraints (e.g., situational factors). Internal attribution will cause individuals to focus on intrinsic motives when seeking explanations for a certain behavior.
On the other hand, external attribution will cause individuals to focus on extrinsic motives, thereby attributing behavior to external factors.

Research on consumer behavior has successfully adopted the attribution theory, suggesting that customers also engage in similar attributional processing when evaluating a corporation's (as opposed to an individual's) behavior (Weiner 2000). Within this framework, consumers attributing internally believe a company participates in CSR because of a sincere interest and concern for the environment. In contrast, consumers attributing externally may conclude that the company is participating in CSR because of situational factors, such as pressure from the market. Furthermore, CSR literature likewise testifies to the involvement of attributional processes in the evaluation of CSR messages (Ellen et al. 2006; Webb and Mohr 1998; Nyilasy et al. 2014).

Following Heider (1944), there are two types of causal attributions for CSR communication: intrinsic motives which refer to dispositions of the actor and extrinsic motives which refer to environmental factors. Translated to CSR communication, consumer reactions may thus range from inferring an attempt to take opportunistic advantage of sustainable development trends (extrinsic motives) to a sincere environmental consciousness as part of the company's DNA (intrinsic motive) (Parguel et al. 2011). Of course, in between these two extreme poles of the continuum, interpretations comprising shades of both poles will be frequent (e.g., imagine a consumer thinking "I think this is a good initiative but I do feel the company could put in even more effort").

In general, when consumers are exposed to an internal CSR claim but have no further information, like a verified third-party label (external label), they are more likely to attribute this communication to the current sustainability trend, which is perceived as an extrinsic motive (Parguel et al. 2011). Whereas internal CSR communication itself will thus rather be perceived as extrinsic, positive external CSR communication should drive attributions to intrinsic motives due to higher levels of credibility and trust (Parguel et al. 2011; Becker-Olsen et al. 2006). Prior research found that consumers are more likely to have negative attitudes, beliefs, and behaviors toward the organization when they assign extrinsic motives compared to intrinsic motives (Becker-Olsen et al. 2006; Ellen et al. 2006; Mohr et al. 1998; Yoon et al. 2006).

Regarding the interaction between external and internal CSR communication, consumers might infer intrinsic or extrinsic motives depending on social consensus, distinctiveness, and consistency (Parguel et al. 2011) as described in the covariation model of Kelley (1973). The current sustainability trend can be compared with the dimension of social consensus and indicates that an effect will be 
attributed to the cause with which it covaries (Parguel et al. 2011). The covariation model also includes two other dimensions: distinctiveness and consistency. Distinctiveness refers to the degree to which the behavior is repeated by the actor in several situations or occurs only within a particular situation, whereas consistency refers to the degree to which a particular behavior is repeated over time (Sjovall and Talk 2004). Thus, when a company's external environmental performance is very positive and combined with an internal CSR claim, this would mean that the company complies with pro-environmental principles in various ways (the engagement is nondistinctive) and on frequent basis (the engagement is consistent) (Parguel et al. 2011). As a result, consumers might conclude that the internal CSR claim advertised is consistent with the company's past behavior due to third-party observations (by the means of an external CSR label) and therefore attribute these claims to intrinsic motives (Parguel et al. 2011).

In contrast, an external CSR label that does not back up an internal CSR claim would make the internal CSR claim distinctive and inconsistent which in turn should drive attributions to more extrinsic motives (Parguel et al. 2011; Sjovall and Talk 2004). Especially in the latter case (i.e., where a mismatch between external labeling and internal claim presence occurs), consumers might be prompted to process the message to a greater extent in so far a perceived incongruence might instigate more elaborate information processing (as opposed to heuristic processing) to resolve the incongruence (cf. Lee and Laproo 2004).

This study seeks to identify how uncertified internal CSR claims and external third-party CSR labels affect consumer response, including corporate credibility, brand evaluation, product experience, purchase intentions, and perceived CSR motives. Based on the foregoing, the following hypotheses are proposed. Starting out from the finding that consumers tend to perceive an external source as more credible than an internal source, it is expected that:

H1 An external CSR label has a more positive impact on consumer responses than an internal CSR claim.

However, the focus of current research is not so much on the main effects of our independent variables (i.e., external label and internal claim presence), but rather on the interaction between external CSR labeling and internal claims. Based on "greenwashing" literature and related topics such as the "self-promoter's paradox" and consumer skepticism, we propose that:

H2 A positive internal claim will negatively affect consumer responses in the presence of a negative (as opposed to a positive) external label.
Finally, based on attribution theory and related insights into the underlying psychological processes involved in claim and label perception, we argue that:

H3 The effects of external labeling and internal claims on consumer responses are mediated by perceptions of CSR motives.

\section{Method}

\section{Procedure and Participants}

To test the influence of CSR communication, either through a company source or an external source, a 3 (external CSR label: positive/negative/no label) $\times 2$ (internal CSR claim: present/absent) randomized between-subject full-factorial design was used. In a hardcopy survey, respondents were exposed to coffee packages which they were asked to rate regarding the attitude toward the brand, purchase intentions, corporate credibility, scent, and brand's motives. In total, 180 Dutch respondents $(55 \%$ female, $45 \%$ male; $56.8 \%$ younger than $23,43.2 \%$ older than 24) participated in a randomized between-subject fullfactorial experiment, yielding 158 usable surveys.

Respondents were randomly assigned to one of the conditions. In order to reduce hypothesis guessing, an unobtrusive explanation was given to them. Subjects were thus informed that the purpose of this study was to get an understanding of general attitudes and beliefs toward the product packaging. After being assigned to one of the conditions and having read the general instructions, the product package of the particular condition was given to the participant for a maximum of 2 min, asking them to carefully look at the product package and all features belonging to it as well as to smell the coffee at the end of the survey. Afterward, the survey including manipulation check and the dependent variables scales was handed out. At the end, two demographic questions were asked (age/gender), and respondents were thanked for their participation. Participating in the study took about 5-10 min, and the study design was approved by the Ethical committee of the University of Twente.

\section{Stimulus Material 1: External CSR Label}

Regarding the external CSR label, 4 self-designed labels illustrating positive and negative environmental impacts, respectively, were composed, consisting of two basic elements. Then, based on a pretest, the most optimal label was selected for the main study. Importantly, the external CSR label should clearly communicate its purpose without the provision of additional explanation or information to the 
participants in our study. That is, we wanted to avoid hypothesis guessing and to stay close to everyday shopping situations in which claims and labels are unobtrusively present on product packaging without explicit clarification of their meanings or purposes.

The first basic element depicts (a part of) the official EU eco-label sign, the flower. This feature of the EU eco-label has been adopted in order to assure that the provided external eco-label is third-party certified and qualified by the European Union in order to clearly differentiate it from an internal CSR claim. As it is classified as a Type 1 ecolabel by the International Organization for Standardization (ISO), it serves as third-party certification and as effective reference for indicating third-party agreement (ISO Central Secretariat 2012). Moreover, the EU eco-label could give an important competitive advantage by raising consumer trust (Gallastegui 2002; Collins 1994).

The second basic element of the label includes a green stamp, which writes ECO performance, combined with a rating scale that is placed above the stamp. Regarding the design of the rating scale, priority was placed on comprehensibility and distinctiveness. Based on various multilevel label systems (e.g., the EU Energy Label (European Union On-Line 2015) and the WWF's regulation system for fish (WWF 2002), four different scales were designed. Overall, by means of different stimuli (e.g., color usage, stars), positive and negative ECO influences, respectively, are communicated by means of the scales, see Fig. 1 .

\section{Pretest External CSR Label}

In order to ensure that the environmental performance labels communicate environmental impact as intended, a pretest was conducted prior to the main study. Based on the above-mentioned aspects, the 4 different external labels as presented in Fig. 1 were shown in hardcopy version to 10 students of the University of Twente. During this pretest, respondents were asked to evaluate each of the designed labels by rating them according to several criteria. The instructions during the pretest were as follows: Please rate the presented eco-labels according to the following criteria: (1) "This eco-label indicates the most positive environmental performance"; (2) "This eco-label indicates the most negative environmental performance"; (3) "I can trust this eco-label"; and (4) "This eco-label is realistic and credible". The first two rating criteria are used in order to assess which rating scheme works best for indicating that a product scores high or low on environmental performance. The third criterion is included, because a higher level of trust has been proven to affect the level of attention to an eco-label (Thogersen 1999). Thus, if a label is highly trusted, consumers will pay more attention to it. Finally, asking for credibility and a realistic design is important in order to ensure that the labels could be used in a realistic context and thus really be placed on product packages in supermarkets. Each label was rated by $1-4$ points, giving 4 points to the label providing the best match to the criterion and 1 point for the label providing the worst match. Afterward, a short interview was conducted in order to assess the advantages and disadvantages, respectively, of the favored designs and to get suggestions for possible adjustments.

Regarding the results of the pretest, label A got the lowest scores regarding 3 of the 4 criteria and was thus neither easy to understand nor satisfyingly realistic or credible. Label B got the highest scores for criteria 1 and 2 as well as the highest score for trustworthiness. However, participants indicated that it was less realistic and less credible compared to labels $\mathrm{C}$ and $\mathrm{D}$. While labels $\mathrm{C}$ and $\mathrm{D}$ were equally effective in indicating positive environmental influence, label D proved to be a better indicator for negative environmental influence, was perceived as more trustworthy and gained the highest score on credibility and realism of the label and was therefore selected. Participants stated that the design of label D, which adopted the form of the EU Energy label, both increases the trustworthiness and seems more realistic than the other designs due to its familiarity and the perception that it "could really be a new EU label." In order to increase the comprehensibility of the negative and positive environmental impacts respectively, of label D, which was lower compared to labels B or C, participants stated that the classification from $A-G$ itself is easy to get, but the achieved score has to be highlighted in another way. Seven out of 10 participants stated that the comprehensibility of the achieved score could be increased by highlighting it within the A-G bar and putting the arrow above it or framing it in bold black instead of putting the score next to the classification bar. By adjusting this accordingly, the A-G bar could also get a little bigger, which further increased readability.

\section{Stimulus Material 2: Internal CSR Claim}

Regarding the internal CSR claim, the International Organization for Standardization (ISO) provides several regulation standards for environmental labeling. Due to the ISO regulation standards, especially three factors should be respected in order to prevent to be too vague or nonspecific (ISO Central Secretariat 2012): (1) accurate and not misleading; (2) substantiated (through examples); and (3) unlikely to result in misinterpretation. In line with this, the Global Eco-labeling Network (GEN 2004) indicates that internal CSR claims should promote the usage and efficient management of renewable or sustainable materials. Furthermore, internal CSR claims should be based on life cycle considerations and contain tangible information 
Fig. 1 Results pretest external CSR label (Labels $A-\mathrm{D})$ and final rating (Label $E$ )

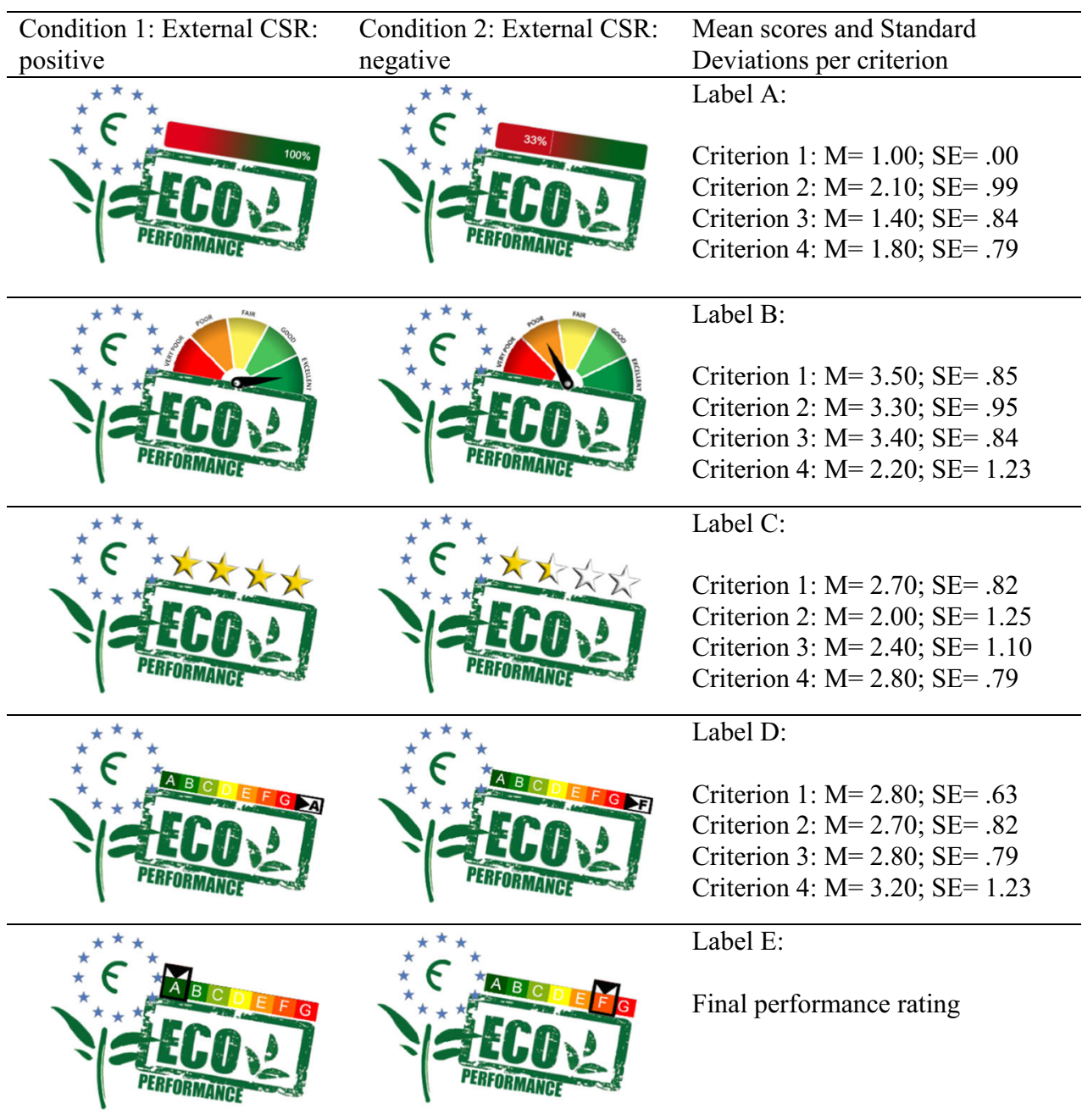

about environmental impact by, for instance, including percentages or other scientific basic information (GEN 2004; CSA 2008). In their guide for environmental claims, the Canadian Standards Association (2008) refers to some effective examples of internal CSR claims which include explanatory statements. Due to these guidelines, internal CSR claims should be formulated as whole sentences and include all standards the ISO provides. An example is "This product uses more recycled material than the model produced in 2006. Better for the environment, better for you!" (CSA 2008). On the basis of all mentioned criteria, the following internal CSR claim is formulated for this study: By incorporating $80 \%$ recycled material, we have reduced waste at the production phase! Healthy for you, healthy for the environment!

\section{Stimulus Material 3: Product Package}

In particular, coffee has been proven to be an effective food product in testing eco-label preferences and influences
(Loureiro and Lotade 2005; De Pelsmacker et al. 2006; Basu and Hicks 2008). Therefore, in this study, the external and internal CSR communication messages were placed on coffee product packages (see Fig. 2). As prior studies have done before, this study uses an unknown fictive brand name to avoid any effects of prior brand familiarity. The brand name that has been chosen is Brew and You Coffee, and none of the pretest respondents had ever heard about this brand before.

In order to assess whether participants properly recognized the manipulations, a manipulation check was included in the main study. As such, all participants, regardless of experimental condition, indicated to what extent they agreed (using 5-point Likert scales) with the statements: "According to the EU, the product is environmentally responsible" and "According to the brand, the product is environmentally responsible." Results show that the external label indeed triggers the belief that the EU is the source $(F(1,174)=334.31, p<.001)$, whereas the uncertified claim does not inspire the belief that the EU is 
Fig. 2 Final stimulus material: product packages

\begin{tabular}{ll}
\hline Condition 1: Positive external & Condition 2: Positive external \\
label and internal claim & label and no internal claim
\end{tabular}

Condition 3: Negative external label and internal claim

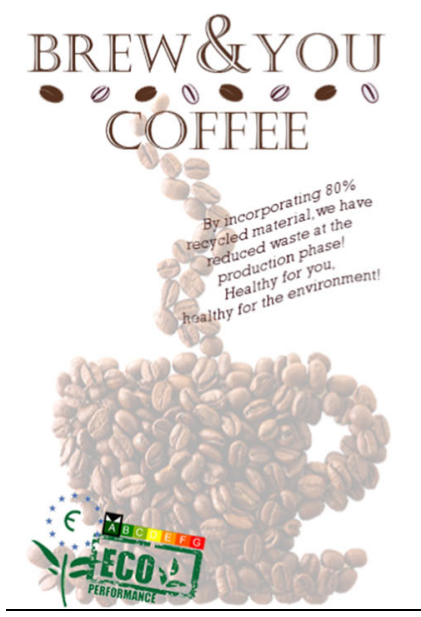

Condition 4: Negative external label and no internal claim
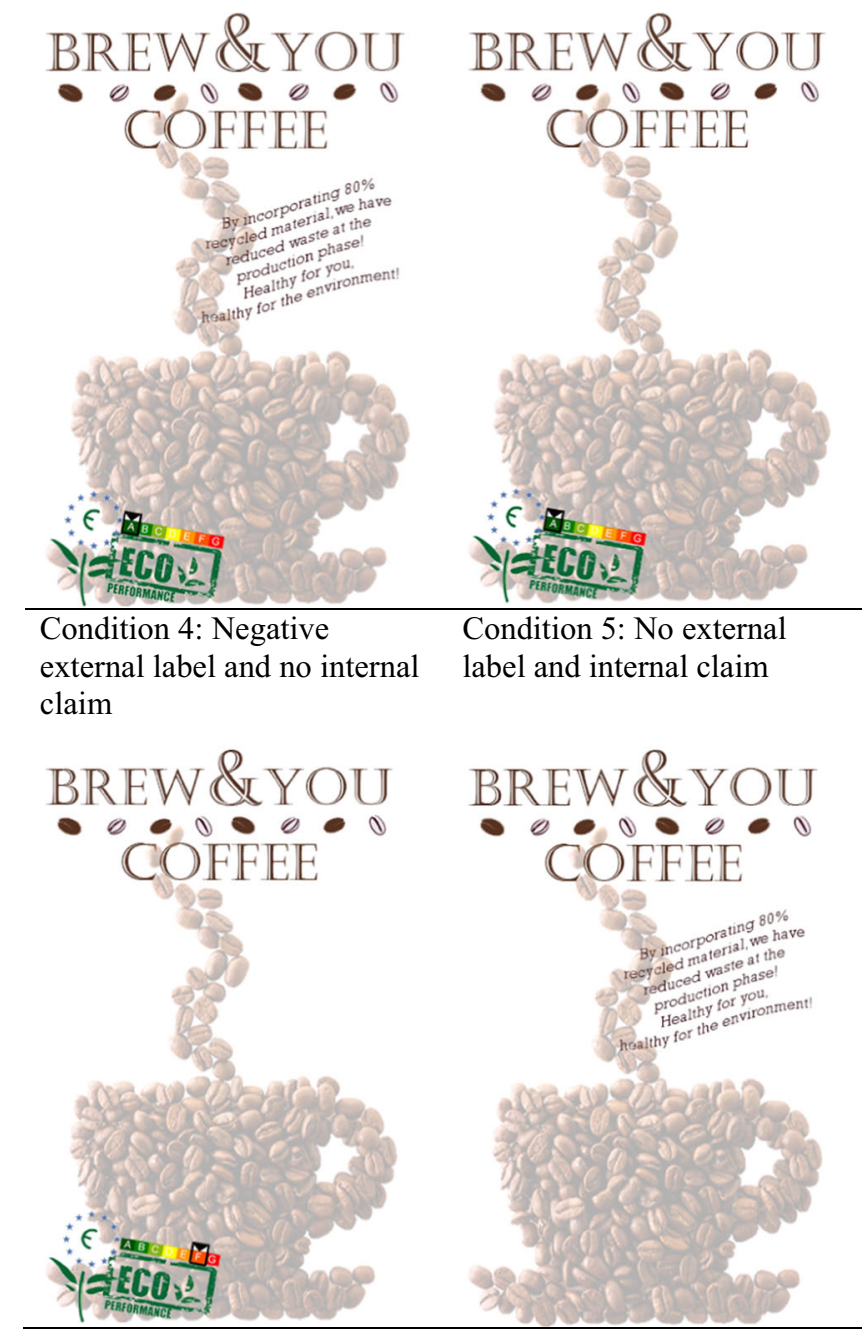

Condition 5: No external

label and internal claim
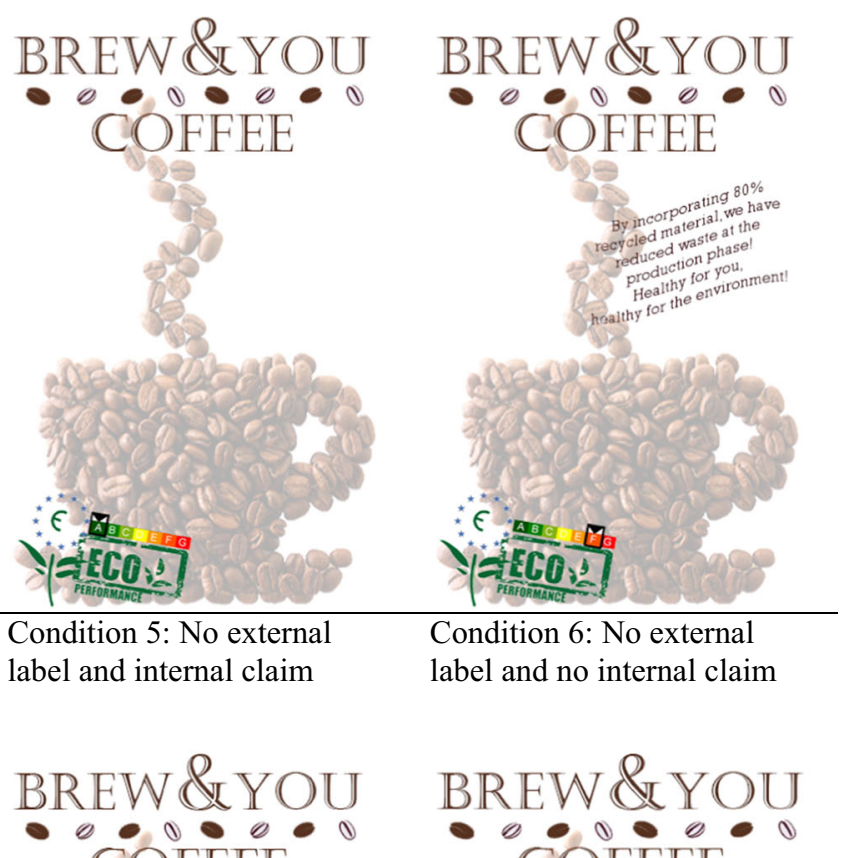
COFFEE
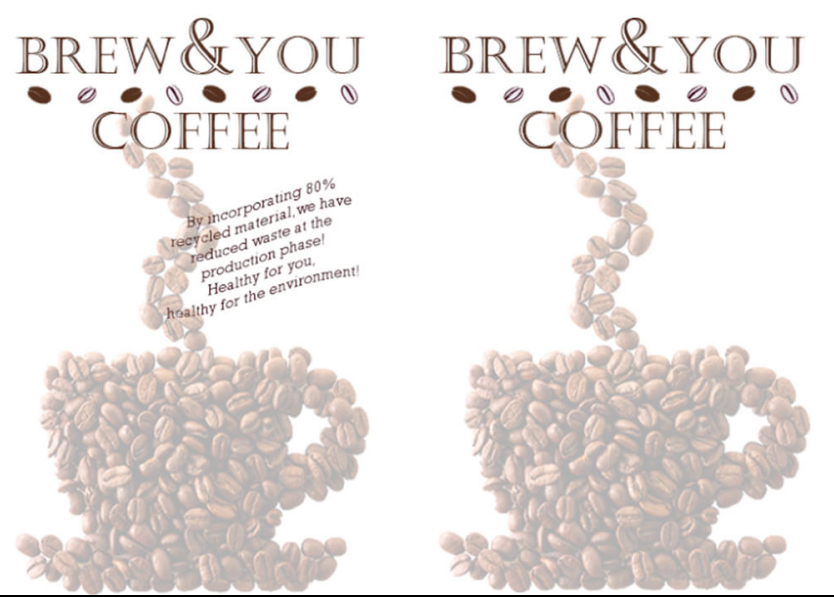

the source $(F<1, n s)$. As for the perception that the brand is the source, the effect of the uncertified claim is (in line with predictions $)$ significant $(F \quad(1,174)=133.06$, $p<.001)$. This time, the effect of the external label is also significant, albeit much smaller; $F(1,174)=3.84$, $p=.02$. This indicates that to a certain effect, using an external label also instills the impression that the brand itself considers the product responsible. These manipulation checks indicate that our designs were perceived as intended and hence confirm their effectiveness.

\section{Dependent Variables}

The dependent variables used in this study include attitude toward brand, corporate credibility, purchase intentions, scent, and CSR motives. In order to measure these variables, validated scales are adopted from the marketing and advertising literature as well as from the literature on CSR.
Attitude toward the brand is measured by a four-item bipolar scale including the adjectives such as (1) dislike/like; (2) unfavorable/favorable; (3) negative/positive; and (4) socially irresponsible/socially responsible. This construct, adopted from Xiaoli and Kwangjun (2007), was found to be reliable with a Cronbach's alpha of .84 .

Corporate credibility was measured by a four-item scale adopted from Becker-Olsen et al. (2006) involving items such as (1) "[Organization] is a firm I can trust"; and (2) "The [Organization] is a firm that cares about its customers," yielding in a satisfactory Cronbach's alpha of .80 .

The purchase intention scale was adopted by Dodds et al. (1991), using a 4-item scale: (1) "I intend to buy a product from this brand"; (2) "Given a choice, my friends will choose a product from this brand"; (3) "There is a strong likelihood that I will buy the product from this brand"; and (4) "I would like to recommend the product 
from this brand to my friends." This construct was found to be reliable with a Cronbach's alpha of .90 .

Adapted from Sörqvist et al. (2015), the scent of the product was tested by asking "What did you think of the smell of the coffee?" Answers could be scored on a fivepoint Likert scale, ranging from "not at all tasty" to "very tasty".

The CSR motives construct was based on Parguel et al. (2011). Three items measured the extent to which participants perceived CSR efforts as intrinsically motivated: (1) "This brand is conscious of the importance of ecological issues"; (2) "This brand has a genuine consciousness regarding ecological problems"; (3) "This brand wants to make consumers aware of ecological issues" (Cronbach's alpha $=.76$ ). These items were measured on a five-point Likert scale, ranging from "strongly agree" to "strongly disagree."

\section{Results}

To reduce the risk of an inflated Type 1 error, first a multivariate ANOVA (MANOVA) was conducted, with "external CSR label" and "internal CSR claim presence" as independent (between subjects) variables and brand attitude, corporate credibility, purchase intention, and product experience as dependent variables. This analysis yielded significant multivariate main effects of both external CSR label $(F(8,344)=6.69, p<.001)$ and claim presence $(F(4,171)=2.53, p<.05)$. The interaction between external CSR label and claim presence was not significant $(F(8,344)=1.33, p=.23)$. These findings warrant further univariate analyses of the main effects of an external CSR label and claim presence.

\section{Brand Attitude}

The main effect of external CSR label was significant ( $F$ (2, $\left.174)=8.21, p<.001, \eta^{2}=.09\right)$. Post hoc comparisons indicate that a positive external label induced a more favorable brand attitude $(M=3.49, \mathrm{SD}=.62)$ compared to a negative label $(M=2.98, \mathrm{SD}=.70, p<.001)$. The differences between the positive and the negative labels compared to the control condition were not significant (both $p$ 's $>.10)$. The main effect of claim presence was not significant $\left(F(1,174)=1.78, p=.18, \eta^{2}=.01\right)$ showing that attitude ratings do not vary as a function of claim presence. Likewise, the interaction between external CSR label and claim presence was not significant $(F<1$, ns).

\section{Corporate Credibility}

For corporate credibility, a similar pattern emerged. Again, the main effect of external CSR label was significant $(F(2$, $\left.174)=16.07, p<.001, \eta^{2}=.16\right)$. Specifically, a positive external label induced a more favorable evaluation $(M=3.25, \quad \mathrm{SD}=.57)$ compared to a negative label $(M=2.62, \mathrm{SD}=.71, p<.001)$. This time, the difference between the negative label and the no-label condition was significant as well $(M=2.62, \mathrm{SD}=.71$ vs. $M=3.01$, $\mathrm{SD}=.55, p<.01)$, with the negative label condition inducing a more negative corporate credibility evaluation compared to the no-label condition. The main effect of claim presence was not significant $(F(1,174)=2.69$, $p=.10, \eta^{2}=.02$ ), showing that corporate credibility ratings do not vary as a function of claim presence. Likewise, the interaction between external CSR label and claim presence was not significant $(F<1$, ns).

\section{Purchase Intention}

With respect to purchase intention, the main effect of external CSR label was significant $(F(2,174)=8.44$, $\left.p<.001, \eta^{2}=.09\right)$. Again, a positive external label induced a more favorable evaluation $(M=2.63, \mathrm{SD}=.78)$ compared to a negative label $(M=2.18, \mathrm{SD}=.82, p<.01)$. However, this time the difference between the negative label and the no-label condition was more pronounced $(M=2.18$, $\mathrm{SD}=.82$ vs. $M=2.74, \mathrm{SD}=.78, p<.001$ ), with the negative label condition inducing a more negative purchase intention compared to the no-label condition. Although the difference between the positive CSR label and the no-label condition is nonsignificant, it is worth noting that here the noCSR label condition induced a slightly higher purchase intention compared to the positive CSR label $(M=2.74$, $\mathrm{SD}=.78$ vs. $M=2.63, \mathrm{SD}=.78)$. The main effect of claim presence was not significant $(F<1$, ns), showing that purchase intentions do not vary as a function of claim presence. This time, the interaction between external CSR label and claim presence was marginally significant ( $F$ (2, $\left.174)=2.76, p=.07, \eta^{2}=.03\right)$, suggesting that in the presence of a claim, purchase intentions are higher when backed up by a positive (as opposed to a negative) CSR label. However, in the absence of a claim, intentions are highest in the no-CSR label condition.

\section{Product Experience (Scent Evaluation)}

As for product evaluation, the main effect of external CSR label was significant $\left(F(2,174)=11.86, p<.001, \eta^{2}=.12\right)$. Post hoc comparisons indicate that a positive external label induced a more favorable scent evaluation $(M=3.15, \mathrm{SD}=1.01)$ compared to a negative label $(M=2.70, \mathrm{SD}=1.14, p=.05)$. Again, the difference between the negative CSR label and the no-CSR label condition was even more pronounced $(M=2.70, \mathrm{SD}=1.14$ vs. $M=3.62, \mathrm{SD}=.98, p<.001)$, with the negative label condition inducing a more negative 
scent evaluation compared to the no-label condition. Surprisingly, the no-label condition also induced a more positive scent evaluation than the positive CSR label condition $(M=3.62$, $\mathrm{SD}=.98$ vs. $M=3.15, \mathrm{SD}=1.01, p=.04)$. The main effect of claim presence was also significant $(F(1,174)=4.70$, $p=.03, \eta^{2}=.03$ ); in the presence (as opposed to the absence) of a claim, scent evaluation was more positive $(M=3.32$, $\mathrm{SD}=1.10$ vs. $M=2.99, \mathrm{SD}=1.09)$. The interaction between external CSR label and claim presence was not significant $\left(F(2,174)=1.14, p=.32, \eta^{2}=.01\right)$.

\section{The Mediating Role of CSR Motives}

In order to further test whether the effects obtained are mediated by perceived CSR motives, mediation analyses were conducted. Based on the criteria for mediation prescribed by Baron and Kenny (1986), "perceived CSR motives" was tested as a mediator of the observed main effects of external CSR label and claim presence on brand attitude, corporate credibility, purchase intention, and product experience, respectively. In order for mediation to apply, effects of both the independent variable (external CSR label/claim presence) and the mediator (perceived CSR motives) on the dependent variable should be significant. Additionally, the effect of the mediator on the dependent variable should be significant. Finally, when both the independent variable and the mediator are inserted as predictors of the dependent variable, the effect of the independent variable should be no longer significant, whereas the effect of the mediator should remain significant. As can be seen in Figs. 3 and 4, this is the case for both brand attitude and corporate credibility. Hence, the main effects of "external CSR label" on brand attitude and corporate credibility are mediated by perceived CSR motives. For purchase intention and product experience, the criteria for mediation were not met.

Finally, we also tested whether the observed main effect of an uncertified label on product experience is also mediated by consumer motives. Although here the criteria for mediation were not met, it is worth noting that the effect of claim presence on the mediator (CSR motives) is significant $(p<.05)$, indicating that, although respondents correctly identified the source of the uncertified claim (as shown by the previously reported manipulation check), they nonetheless considered the uncertified claim as indicative of responsible management.

\section{Discussion}

The objective of the research at hand was to find out to what extent uncertified internal CSR claims, external thirdparty CSR labels, and the combination of both influence consumer attitudes toward the CSR messages and toward the source (brand/company) behind these messages. A second objective was to lay bare the underlying process and thus to address whether perceived intrinsic and extrinsic motives steer such evaluations. This study broadly posited that an internal claim will only be effective to the extent that it is backed up by an extrinsic CSR label.

In line with the presumed importance of an extrinsic CSR label (and confirming H1), the results showed that especially an external CSR label affects consumer responses toward the firm. The effects of the internal claim were nonsignificant (except on attributed motives). Furthermore, the proposed interaction between internal claim and external CSR label (H2) only surfaced for purchase intentions. Finally, perceived CSR motives served as a mediator between an external CSR label and corporate credibility and brand attitude, respectively, confirming the importance of attribution theory in this context (H3).

First of all, regarding external labeling, in line with prior studies (Parguel et al. 2011; Grankvist et al. 2004; Swaen and Van Hamme 2004), our findings support the idea that a positive external CSR label induced more favorable consumer responses (including brand attitude, corporate credibility, purchase intention, and scent experience) compared to a negative label. Surprisingly, with respect to
Fig. 3 Mediation analysis for the main effect of external CSR rating on brand attitude

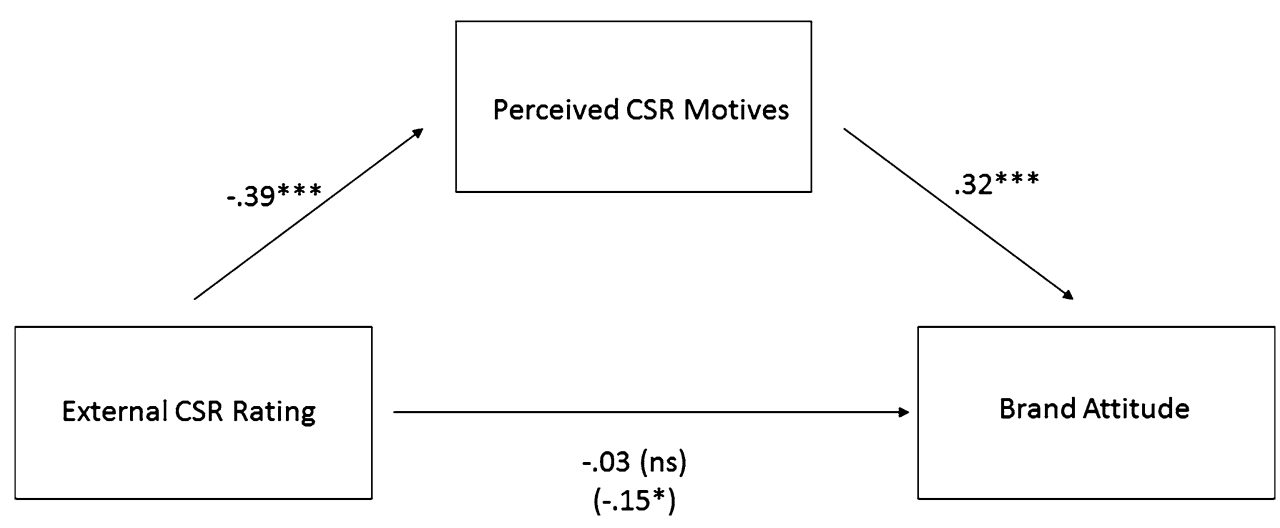


Fig. 4 Mediation analysis for the main effect of external CSR rating on corporate credibility

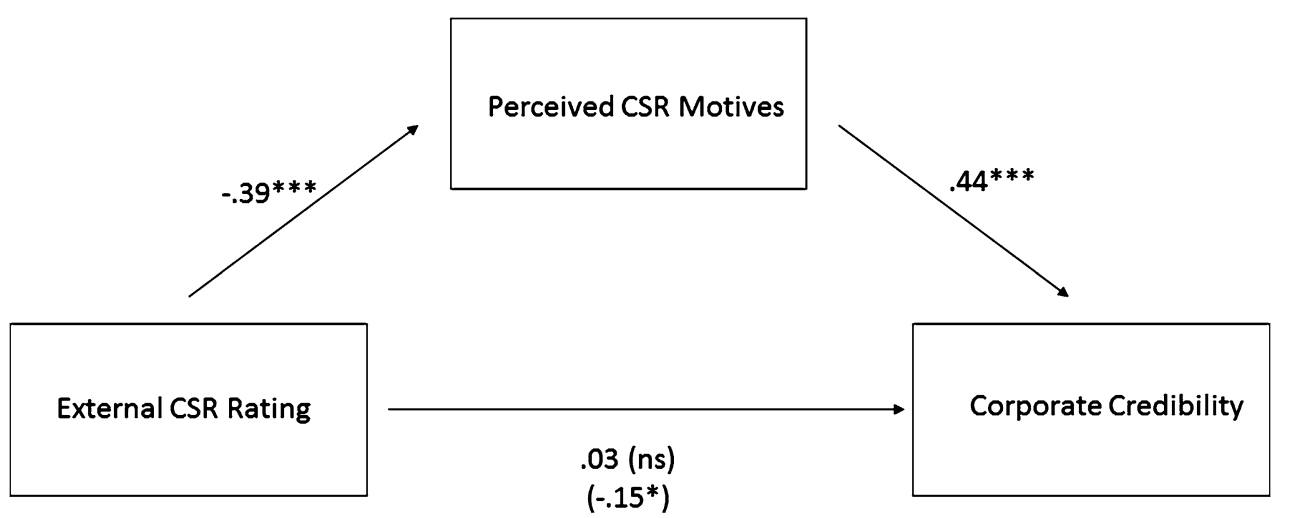

product experience (scent evaluation) and purchase intention, our results indicate that the absence (as opposed to the presence) of an external label might induce more positive consumer responses (although in our study this difference was significant for scent evaluation only). Although the benefits of an external positive label in comparison to "no label" are thus variable dependent on the outcome measure at stake, in our study negative external CSR labeling really proved to have a negative effect on consumer evaluations. Arguably, virtuous companies do not benefit from their positive environmental behaviors compared to "neutral" firms, because consumers infer a general climate of confidence in companies, as long as they have not been associated with any kind of crisis (Parguel et al. 2011). Therefore, in response to the profusion of CSR claims, negative external CSR labels could serve as more accurate help in consumer evaluation of companies' environmental performances.

In line with the foregoing, our results reveal that the presence of an uncertified internal CSR claim might also instill perceptions of a responsible brand (as indicted by the effect of an uncertified internal claim on perceived CSR motives). Consumers do thus not generally infer perceived self-interest by the company only because the CSR information is presented by a low credibility source as suggested by Dawkins (2004). This study gives reason to assume that, up to a certain level, consumers might also attribute intrinsic motives to uncertified internal CSR claims, because (regardless of its source) CSR itself may be viewed positively (Ellen et al. 2006). This makes it all the more important to provide better guidance and explanations toward consumers with respect to the status and information value of different claim and label types. Note however that the effects of internal claim presence on the (other) outcome variables in our study were not significant; hence, no firm conclusions as to the overall benefits of internal CSR claims are warranted here.

Importantly, the proposed interplay between internal claim and external label did not surface in our study (except for a marginal interaction effect on purchase intentions). Next to that, no evidence for the perceived greenwashing effect (Nyilasy et al. 2014) was found. The existence of inconsistent CSR information did not invite consumers to perceive a company as hypocritical and thus did not jeopardize the image of the company by affecting consumer attitudes negatively, as reported by Wagner et al. (2009).

These findings are surprising, as a large body of literature found evidence for the greenwashing effect in green advertising (Delmas and Burbano 2011; Nyilasy et al. 2014; De Vries et al. 2013). However, Kim and Lee (2012) found (in line with our findings) that even though CSR communication had been inconsistent and extrinsic motives were perceived, consumers still tended to think that the organization was sincere in supporting environmental issues. Perhaps then, when confronted with inconsistent information, consumers may engage in a line of reasoning such as "the company does its best in providing ecologically sound products but is still in the beginning phase, and hence is not seen as fully ecological according to external standards."

Similarly, our results suggest that a negative external label (as opposed to no label) may nonetheless instill perceptions of responsible management, arguably because the presence of an external label in itself acts as a cue, implicitly communicating a company's sincere intentions. Again, this type of "consumer naivety" highlights the need for clear communication and consequent policy making. Finally, our study confirms the importance of attribution theory as it allowed us to account for the findings presented in terms of consumer perceptions of CSR motives.

\section{Limitations and Directions for Future Research}

Several limitations should be acknowledged when interpreting the findings of this study. First, this research is restricted to one specific product context, the food sector, which leads to the implication that future experiments 
should concentrate on investigating this topic within other sectors. Regardless of product category, follow-up studies could also zoom in on long-term effects such as brand loyalty and corporate reputation. Finding effects on more direct measures such as product evaluation and purchase intention in the current study indicate that such studies are worthwhile as product appreciation and repeat purchases are the building blocks necessary for loyalty and corporate reputation to develop. Furthermore, as corporate credibility is something to develop over multiple exposures to the company in varying contexts, it is also worthwhile to investigate how, for instance, exposures to a negative external label would influence perceptions of a company generally regarded as socially responsible. On the other hand, consumers might generally pay more attention to product packaging when product and brand are new, and they are not yet routine purchases. Hence, for several reasons, it would be worth investigating how single versus multiple exposures to CRS labels affect consumer responses for new and existing brands.

A second limitation concerns the selection of our external CSR label and internal CSR claim; both were represented by only one variant and hence by one type of framing. Arguably, depending on the type and extent of information provided (external CSR label) and realism or outspokenness (internal claim), attributions made by consumers may vary. Related to the foregoing, we can also not rule out that differences in design or information density might have affected our results. For instance, different designs may vary in the extent to which they trigger perceptions of professionalism or seriousness, which might also affect label credibility and related measures.

Moreover, even though the used material has been presented in a realistic way by using hardcopy surveys, the setting stays artificial. Presenting the stimulus material in a natural context (e.g., a supermarket) next to other product packages may cause participants to process the product packages differently. In addition, next to the company's name, the CSR communication was the only information presented, which is different for real products that (at least) also carry nutrition facts. This exiguous change in the presentation of information may have influenced the perceived evaluations of the product and the CSR communication(s). Future research could use more information on the product packages and present them in a more realistic setting.

\section{Conclusion}

Using attribution theory, this study is the first to investigate the interplay between both positive and negative external CSR labeling and internal CSR claims on product packages. Findings of the present study offer valuable insights on how to effectively communicate CSR efforts in the food sector. Moreover, our findings show that consumers may still somewhat "naively" take an internal claim for granted rather than questioning its authenticity. An explicit negative label, on the other hand, did prove to be effective in guiding participants to an interpretation of CSR motives in line with this external assessment. Therefore, we argue that it is important to introduce a multilevel external rating system that provides both positive and negative external CSR information. Such a rating system might well prove to be an effective tool for reducing greenwashing and contributing to a truly responsible climate. Furthermore, such a system has the potential to instigate the development of pro-environmental initiatives of nonvirtuous firms as they sooner or later would have to adopt environmental friendly production methods in order to secure their share in the market.

\section{Compliance with Ethical Standards}

Conflict of interest The authors declare no conflict of interest.

Open Access This article is distributed under the terms of the Creative Commons Attribution 4.0 International License (http://crea tivecommons.org/licenses/by/4.0/), which permits unrestricted use, distribution, and reproduction in any medium, provided you give appropriate credit to the original author(s) and the source, provide a link to the Creative Commons license, and indicate if changes were made.

\section{References}

Ashforth, B. E., \& Gibbs, B. W. (1990). The double-edge of organizational legitimation. Organization Science, 1(2), 177-194.

Becker-Olsen, K. L., Cudmore, B. A., \& Hill, R. P. (2006). The impact of perceived corporate social responsibility on consumer behavior. Journal of Business Research, 59(1), 46-53.

Baron, R. M., \& Kenny, D. A. (1986). The moderator-mediator variable distinction in social psychological research: Conceptual, strategic and statistical considerations. Journal of Personality and Social Psychology, 51, 1173-1182.

Basu, A. K., \& Hicks, R. L. (2008). Label performance and the willingness to pay for fair trade coffee: a crossnational perspective. International Journal of Consumer Studies, 32(5), 470-478.

Canadian Standards Association. (2008). Environmental claims: A guide for industry and advertisers. http://www.competitionbur eau.gc.ca/eic/site/cb-bc.nsf/vwapj/guide-for-industry-and-adverti sers-en.pdf/\$FILE/guide-for-industry-and-advertisers-en.pdf.

Childs, C., \& Whiting, S. (1998). Eco-labelling and the green consumer. Bradford: Department of Environmental Science (University of Bradford).

Collins, L. (1994). Environmental performance and technical innovation: The pulp and paper industry as a case in point. Technology in Society, 16, 427-446.

Dawkins, J. (2004). Corporate responsibility: The communication challenge. Journal of Communication Management, 9(2), 108-119.

De Pelsmacker, P., Janssen, W., Sterckx, E., \& Mielants, C. (2006). Fair trade beliefs, attitude and buying behaviour of Belgian 
consumers. International Journal of Voluntary Sector Marketing, 11(2), 125-138.

De Vries, G., Terwel, B. W., Ellemers, N., \& Daamen, D. D. L. (2015). Sustainability or profitability? How communicated motives for environmental policy affect public perceptions of corporate greenwashing. Corporate Social Responsibility and Environmental Management, 22(3), 142-154.

Delmas, M. A., \& Burbano, V. (2011). The drivers of greenwashing. California Management Review, 54(1), 64-87.

Dodds, W. B., Monroe, K. B., \& Grewal, D. (1991). Effects of price, brand, and store information on buyers' product evaluations. Journal of Marketing Research, 28(3), 307-319.

Du, S., Bhattacharya, C. B., \& Sen, S. (2010). Maximizing business returns to corporate social responsibility (CSR): The role of CSR communication. International Journal of Management Reviews, 12(1), 8-19.

Ellen, P. S., Webb, D. J., \& Mohr, L. A. (2006). Building corporate associations: Consumer attributions for corporate socially responsible programs. Journal of the Academy of Marketing Science, 34(2), 147-157.

European Union On-Line. (2015). Council directive 92/75/EEC (31992L0075) of 22 September 1992. Retrieved 28 April 2015. http://ec.europa.eu/energy/en/topics/energy-strategy.

Gallastegui, I. G. (2002). The use of eco-labels: A review of the literature. European Environment, 12, 316-331.

Giridhar, T. R. (1998). Eco-labelling: A comparative analysis. Colourage, 45(6), 27-30.

Global Eco-labelling Network. (2004). Introduction to eco-labelling. http://www.globaleco-labelling.net/docs/documents/intro_to_ eco-labelling.pdf.

Grankvist, G., Dahlstrand, U., \& Biel, A. (2004). The impact of environmental labelling on consumer preference: Negative vs. positive labels. Journal of Consumer Policy, 27(2), 213-230.

Heider, F. (1944). Social perception and phenomenal causality. Psychological Review, 51(6), 358.

Kelley, H. H. (1973). The processes of causal attribution. American Psychologist, 28(2), 107.

Kim, H. S. (2011). A reputational approach examining publics' attributions on corporate social responsibility motives. Asian Journal of Communication, 21(1), 84-101.

Kim, S., \& Lee, Y. J. (2012). The complex attribution process of CSR motives. Public Relations Review, 38(1), 168-170.

Lee, A. Y., \& Labroo, A. A. (2004). Effects of conceptual and perceptual fluency on brand evaluation. Journal of Marketing Research, 41(2), 151-165.

Loureiro, M. \& Lotade, J. (2005). Do fair trade and eco-labels in coffee wake up the consumer conscience? Ecological Economics, 53(1), 129-138.

Mickels, A. (2009). Beyond corporate social responsibility. Hastings International and Comparative Law Journal, 32, 271-300.

Mohr, L. A., Eroğlu, D., \& Ellen, P. S. (1998). The development and testing of a measure of skepticism toward environmental claims in marketers' communications. The Journal of Consumer Affairs, 32(1), 30-55.

Mohr, L. A., Webb, D. J., \& Harris, K. E. (2001). Do consumers expect companies to be socially responsible? The impact of corporate social responsibility on buying behavior. The Journal of Consumer Affairs, 35(1), 45-72.

Mondelaers, K., Verbeke, W., \& Van Huylenbroeck, G. (2009). Importance of health and environment as quality traits in the buying decision of organic products. British Food Journal, 111(10), 1120-1139.

Morsing, M., \& Schultz, M. (2006). Corporate social responsibility communication: Stakeholder information, response and involvement strategies. Business Ethics: A European Review, 15(4), 323-338.
Nyilasy, G., Gangadharbatla, H., \& Paladino, A. (2014). Perceived greenwashing: The interactive effects of green advertising and corporate environmental performance on consumer reactions. Journal of Business Ethics, 125(4), 693-707.

Parguel, B., Benoît-Moreau, F., \& Larceneux, F. (2011). How sustainability ratings might deter 'greenwashing': A closer look at ethical corporate communication. Journal of Business Ethics, 102(1), 15-28.

Pomering, A., \& Johnson, L. W. (2009). Constructing a corporate social responsibility reputation using corporate image advertising. Australasian Marketing Journal (AMJ), 17(2), 106-114.

Rashid, N. R. N. A. (2009). Awareness of eco-label in Malaysia's green marketing initiative. International Journal of Business and Management, 4(8), 132.

Schuldt, J. P., \& Hannahan, M. (2013). When good deeds leave a bad taste. Negative inferences from ethical food claims. Appetite, 62, 76-83.

ISO Central Secretariat (2012). Environmental labels and declarations. How ISO standards help. http://www.iso.org/iso/environ mental-labelling.pdf.

Sen, S., \& Bhatachharya, C. B. (2001). Does doing good always lead to doing better? Consumer reactions to corporate social responsibility. Journal of Marketing Research, 38(2), 225-243.

Sjovall, A. M., \& Talk, A. C. (2004). From actions to impressions: Cognitive attribution theory and the formation of corporate reputation. Corporate Reputation Review, 7(3), 269-281.

Sörqvist, P., Haga, A., Holmgren, M., \& Hansla, A. (2015). An ecolabel effect in the built environment: Performance and comfort effects of labeling a light source environmentally friendly. Journal of Environmental Psychology, 42, 123-127.

Swaen, V., \& Van Hamme, J. (2004). The use of corporate social responsibility arguments in communication campaigns: Does source credibility matter? In Advances in consumer research.

TerraChoice. (2010). The sins of greenwashing: Home and family edition 2010: A report on environmental claims made in the North American consumer market. Retrieved 18 Dec 2011. http://sinsofgreenwashing.org/?dl_id=102.

Thygersen, J. (1999). The ethical consumer. Moral norms and packaging choice. Journal of Consumer Policy, 22(4), 439-460.

Vanhamme, J., \& Grobben, B. (2009). "Too good to be true!" The effectiveness of CSR history in countering negative publicity. Journal of Business Ethics, 85(2), 273-283.

Wagner, T., Lutz, R. J., \& Weitz, B. A. (2009). Corporate hypocrisy: Overcoming the threat of inconsistent corporate social responsibility perceptions. Journal of Marketing, 73(6), 77-91.

Webb, D. J., \& Mohr, L. A. (1998). A typology of consumer responses to cause-related marketing: From skeptics to socially concerned. Journal of Public Policy \& Marketing, 17(2), 226-238.

Weiner, B. (2000). Attributional thoughts about consumer behavior. Journal of Consumer Research, 27(3), 382-387.

WWF:s recommendation on fish and the environment (2002). Second edn. Retrieved 30 April 2015. http://www.wwf.org.uk/filelibrary/ pdf/feedingthefish.pdf.

Xiaoli, N., \& Kwangjun, H. (2007). Consumer responses to corporate social responsibility (CSR) initiatives. Journal of Advertising, 36(2), 63-74.

Yoon, Y., Gürhan-Canli, Z., \& Schwarz, N. (2006). The effect of corporate social responsibility (CSR) activities on companies with bad reputations. Journal of Consumer Psychology, 16(4), 377-390. 